\title{
PENGOLAHAN DATA BERBANTU SOFTWARE SPSS BAGI PERANGKAT DESA DI KECAMATAN BUNTU PANE KABUPATEN ASAHAN
}

\author{
Pristiyanilicia Putri $^{1}$, Chitra latiffani ${ }^{2}$ \\ ${ }^{1,2}$ Sistem Informasi, STMIK ROYAL Kisaran \\ email: pristianiliciaputri@gmail.com, artihclatiffani@gmail.com
}

\begin{abstract}
Community Service Activity is conducted in the form of training in the utilization of information technology in data processing that aims to provide knowledge and skills for the village apparatus in Buntu Pane subdistrict in data processing that is computerized as one way in making an institution decision. The target in this activity is the village apparatus in Buntu Pane sub-district which is approximately 25 people. Training in data processing is done by lecture method, demonstration, and practice with a question and answer. The lecture method is used to explain the introductory concept of the introduction of SPSS software as one of the media in data processing. Demonstration method is used to show a working process that is stages of recognizing the existing tools in the software SPSS and know each function, while the method of practice to practice data processing based on information technology by processing a certain data. While the question and answer method to give the participants the opportunity in consultation to overcome obstacles in understanding the material already obtained. The end result of activities is expected to accelerate and facilitate the employees in decision making for the future.
\end{abstract}

Keywords: Data processing, SPSS software, computer, information technology

\begin{abstract}
Abstrak: Pengabdian kepada masyarakat merupakan salah satu bentuk Tridarma perguruan Tinggi yang harus dilaksanakan oleh seorang dosen. Pada kegiatan pengabdian pada masyarakat ini akan mengimplementasikan kompetensi keilmuan yang dimiliki agar memberikan manfaat bagi masyarakat, dimana kegiatan ini dilakukkan dalam bentuk pelatihan dalam pemanfaatan teknologi informasi dalam pengolahan data yang bertujuan memberikan pengetahuan dan keterampilan bagi para perangkat desa di kecamatan Buntu Pane dalam pengolahan data yang bersifat komputerisasi sebagai salah satu cara dalam pengambilan keputusan sebuah instansi. Sasaran dalam kegiatan PKM ini adalah para perangkat desa di kecamatan Buntu Pane yang berjumlah lebih kurang 25 orang. Pelatihan dalam pengolahan data ini dilakukan dengan metode ceramah, demonstrasi, dan latihan yang disertai tanya jawab. Metode ceramah digunakan untuk menjelaskan konsep pengantar dari pengenalan software SPSS sebagai salah satu media dalam pengolahan data. Metode demonstrasi dipakai untuk menunjukkan suatu proses kerja yaitu tahap-tahap mengenalan tool-tool yang ada pada software SPSS dan mengetahui masing-masing fungsinya, sedangkan metode latihan untuk mempraktikkan pengolahan data berbasis teknologi informasi dengan mengolah sebuah data tertentu. Sementara metode tanya jawab untuk memberi kesempatan para peserta dalam berkonsultasi untuk mengatasi kendala dalam memahami materi yang sudah didapat. Hasil akhir dari kegiatan PKM ini diharapkan dapat mempercepat dan mempermudah para pegawai dalam pengambilan keputusan untuk masa yang akan datang.
\end{abstract}

Kata kunci: Pengolahan data, Software SPSS, komputer, teknologi informasi 
Vol. 1, No. 2, Jul 2018, hlm. 51 - 56

ISSN 2614-7912 (cetak)

ISSN 2622-3813 (online)

Available online at http://jurnal.stmikroyal.ac.id/index.php/jurdimas

\section{PENDAHULUAN}

Program pengabdian kepada masyarakat yang bertemakan pengolahan data berbantu software SPSS merupakan salah satu program utama dari Tridarma perguruan tinggi dosen STMIK Royal Kisaran yang bertujuan untuk memberikan pengetahuan dan keterampilan bagi masyarakat yang berkaitan dengan teknologi informasi dibidang pengolahan data secara komputerisasi. Kemampuan dalam menggunakan komputer sangat diperlukan dalam bidang pekerjaan kehidupan sehari-hari. Komputer ini telah dikenal di berbagai aspek kehidupan dan aspek pekerjaan sesuai dengan target pemerintah yang bertujuan untuk mengembangkan program Information Communication Technologies (ICT) serta membentuk generasi-generasi digital yang tidak gagap teknologi di Indonesia.

Pada dasarnya masih banyak masyarakat yang memiliki pengetahuan minim sekali tentang komponenkomponen komputer, terutama bagi para pekerja dalam hal ini adalah karyawankaryawan atau perangkat pemerintah yang baru mengenal komputer. Padahal kalau diperhatikan banyak sekali komponen pada komputer yang mesti diketahui agar nantinya tahu seperti apa proses kerja komputer tersebut. Prinsip dasar dalam komponen komputer adalah hardware, software dan proses pengiriman data atau informasi dari pengirim ke penerima melalui suatu media komunikasi tertentu.

Oleh karena itu, Perguruan Tinggi STMIK Royal Kisaran dengan dasar ini tertarik untuk mengadakan pengabdian di Kecamatan Buntu Pane bagi para karyawan dengan kegiatan pengolahan data berbasis SPSS yang dapat berguna bagi pegawai tersebut dalam hal pengolahan data yang nantinya sangan berguna dalam pengambilan keputusan dan menambah pengetahuan di bidang komputer kepada para karyawan dengan harapan nantinya mereka dapat menerapkan ilmu yang diperoleh dalam mengambil sebuah keputusan.

\section{METODE}

Metode yang digunakan dalam menerapkan kegiatan pengabdian kepada masyarakat adalah pelatihan yang meliputi Metode ceramah digunakan untuk menjelaskan konsep pengantar dari pengenalan software SPSS sebagai salah satu media dalam pengolahan data. Metode demonstrasi dipakai untuk menunjukkan suatu proses kerja yaitu tahap-tahap mengenalan tool-tool yang ada pada software SPSS dan mengetahui masing-masing fungsinya, dan metode latihan untuk mempraktikkan pengolahan data berbasis teknologi informasi dengan mengolah sebuah data tertentu. Sementara metode tanya jawab untuk memberi kesempatan para peserta dalam berkonsultasi untuk mengatasi kendala dalam memahami materi yang sudah didapat

\section{PEMBAHASAN}

Statistika adalah pengetahuan yang berkaitan dengan cara-cara pengumpulan, penyajian, analisis, dan penggunaan data numerik untuk membuat kesimpulan dan keputusan berdasarkan kumpulan data dan analisis yang dilakukan dalam keadaan ketidakpastian di bidang ekonomi, bisnis, ilmu pengetahuan sosial serta ilmu pengetahuan alam.

Sebagai suatu bidang studi, statistika mempunyai empat bagian utama, yaitu :

1.Statistik Deskriptif

Statistik Deskriptif berhubungan dengan peringkasan seperangkat data dan penyajiannya ke dalam bentuk yang dapat dipahami (lebih menekankan pada teknik 
Vol. 1, No. 2, Jul 2018, hlm. 51 - 56

ISSN 2614-7912 (cetak)

ISSN 2622-3813 (online)

Available online at http://jurnal.stmikroyal.ac.id/index.php/jurdimas

pengumpulan, pengolahan, penyajian dan penganalisisan data kuantitatif secara deskriptif guna memberikan gambaran yang teratur mengenai suatu persoalan). Perhitungan rata-rata dan distribusi frekuensi, angka indeks, dan analisis time series merupakan pokok-pokok bahasan dalam statistik deskriptif.

\section{Probabilitas}

Probabilitas adalah suatu angka yang mengukur frekuensi relatif dari suatu kejadian dalam jangka panjang atau menunjukkan suatu tingkat kepercayaan. Pemakaian konsep-konsep probabilitas menjadi dasar/landasan dalam mempelajari teori keputusan secara statistik dan statistik inferensi.

\section{Teori keputusan secara statistik}

Analisis keputusan secara statistik berhubungan dengan pengambilan keputusan bila alternatif-alternatif tindakan diketahui, akan tetapi hasil dari masing-masing tindakan berbeda-beda. Analisis keputusan secara statistik akan memberikan jawaban yang paling baik dalam situasi yang tidak pasti atau penuh resiko.

\section{Statistik Inferensi}

Statistik Inferensi adalah suatu pernyataan mengenai suatu populasi yang didasarkan pada informasi dari sampel random yang diambil dari populasi itu (tidak hanya menekankan pada teknik pengumpulan, pengolahan, penyajian dan penganalisisan data saja, tetapi juga teknik penarikan kesimpulan dan pembuatan keputusan yang dapat dipertanggungjawabkan).

Tahap-tahap penyelesaian masalah secara statistik adalah :
1. Mengidentifikasi persoalan
Pertama kali persoalan yang dihadapi harus difahami dan didefinisikan

dengan benar. Pada tahap ini informasi kuantitatif sangat bermanfaat.

Tahap ini termasuk kedalam perencanaan penelitian, hal ini diperlukan sebagai pedoman dalam mengumpulkan data kasar secara terarah dan ekonomis sehingga peneliti mengerti betul pokok persoalan yang menjadi objek penelitian.

2.Mengumpulkan data atau fakta-fakta yang ada

Data harus dikumpulkan dengan tepat dan selengkap mungkin serta berhubungan dengan persoalan yang dihadapi.

3.Mengumpulkan data asli yang baru

Seringkali data yang diperlukan tidak tersedia pada sumber-sumber yang ada, karena itu harus dikumpulkan sendiri (misalnya survey, kuestioner, dll).

4.Klasifikasi data

Setelah data dikumpulkan, data dan fakta dikelompokkan sesuai dengan tujuan studi. Mengidentifikasi data berdasarkan kemiripan sifat-sifatnya dan menyusunnya ke dalam kelompokkelompok dinamakan klasifikasi. Tahap ini termasuk dalam tahap pengolahan data.

5.Penyajian Data

Ringkasan informasi disajikan dalam bentuk tabel, diagram, dan ukuranukuran deskriptif seperti rata-rata dan dispersi, dll.

6.Analisis Data dan Penarikan

Kesimpulan

Penganalisisan data merupakan proses pemilihan metode yang tepat yang sesuai dengan tujuan penelitian. Hasil dari analisis diinterpretasikan sehingga data yang terkumpul tersebut dapat memberikan gambaran mengenai penelitian yang dilakukan.

Jika data dikumpulkan dari sampel (bukan populasi), maka berdasarkan ukuran-ukuran deskriptif yang telah dihitung, dilakukan pendugaan parameter populasi dan pengujian asumsi parameter atau ciri-ciri populasi. 
Vol. 1, No. 2, Jul 2018, hlm. $51-56$

Available online at http://jurnal.stmikroyal.ac.id/index.php/jurdimas

Pendugaan dan pengujian nilai parameter populasi berdasakan informasi dari sampel merupakan unsur utama dalam statistik inferensi. Kemudian analisis menafsirkan hasil pendugaan dan membuat kesimpulan atas hasil pengujian

\section{Prosedur Analisis Data dengan SPSS}

a. Hidupkan komputer, lanjutkan dengan mengklik kotak START pada kiri bawah.

b. Arahkan kursor ke menu program dan geserlah kekanan dengan hati-hati menuju menu SPSS.

c. Klik mouse setelah kursor berada persis pada menu SPSS

d. Maka akan tampak gambar menu utama software SPSS seperti berikut ini

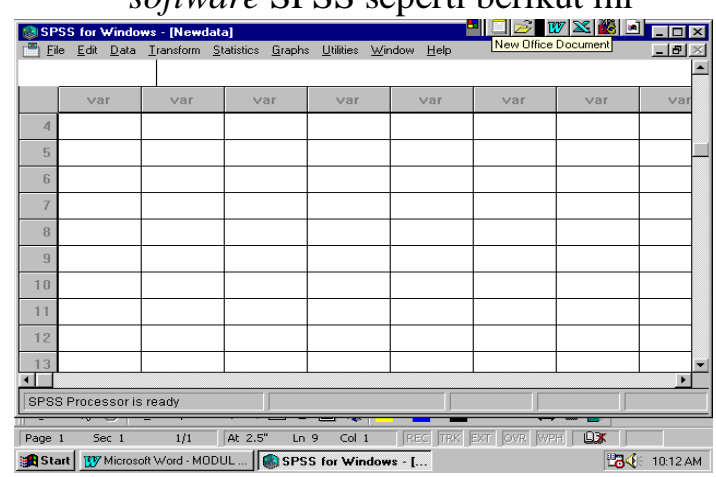

Gambar 1. Tampilan menu utama software SPSS

e. Langkah awal sebelum proses analisis dimulai adalah melakukan entry data.

f. Menentukan nama variabel yang digunakan untuk menampung setiap elemen data yang dimiliki.

g. Masukkan setiap nama tersebut ke dalam program SPSS sesuai dengan jenis data yang ada (string, numeric, date, atau yang lainnya).

h. Untuk memasukkan nama variabel tersebut lakukanlah dengan cara mengklik DATA - DEFINE VARIABLE

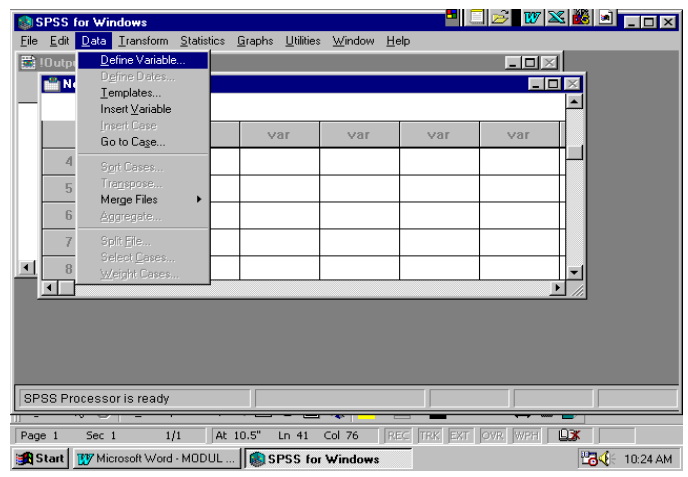

Gambar 2. Memasukkan nama variabel

i. Setelah itu akan muncul kotak dialog define variable sebagai berikut.

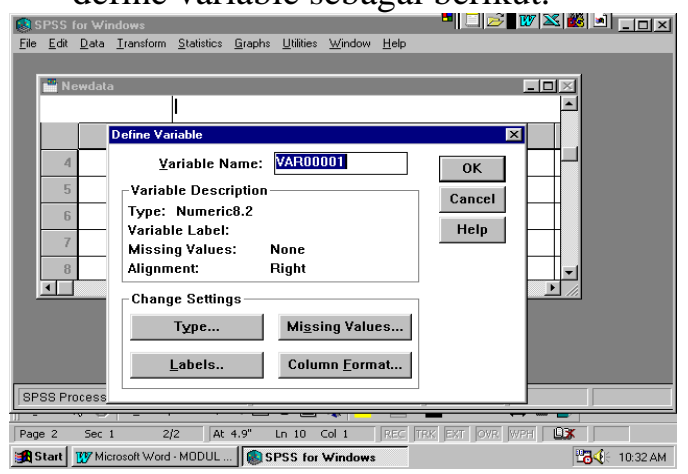

Gambar 3. Kotak dialog define variable

j. Isikan pada kotak variable name nama variabel pertama yaitu STATUS

k. Kemudian klik menu Type pada menu define variable tersebut.

1. Pilih tipe variabel STATUS tersebut sebagai variabel string (huruf). Oleh karena itu kliklah lingkaran String. Kotak width kita klik apabila kita ingin merubah lebar kolom dari 8 karakter menjadi lebih kecil atau lebih besar dengan cara mengganti angka 8 yang ada pada kotak tersebut dengan angka lain yang sesuai.

m. Maka di kolom paling kiri akan tertera nama variabel STATUS. Geserlah krusor anda pada krusor kedua (samping kanan variabel STATUS persis). 
Vol. 1, No. 2, Jul 2018, hlm. $51-56$

Available online at http://jurnal.stmikroyal.ac.id/index.php/jurdimas

n. Lakukan kembali perintah ke $8 \mathrm{~s} / \mathrm{d}$ perintah ke 13 untuk memasukkan nama variabel dan tipe variabel satu per satu. Namun untuk tipe data pada perintah ke 12 gantikan dari string (STATUS) ke numerik dengan cara mengklik lingkaran numeric.

o. Setelah semua nama variabel kita masukkan, barulah kita mulai mengentry data setiap variabel ke dalam kolom variabelnya masingmasing.

p. Setelah semua nama variabel dan isinya dientry

q. Setelah seluruh data dientry maka langkah selanjutnya adalah mengolah hasil dan melakukan uji hipotesis

Berikut ini dokumentasi kegiatan pengabdian kepada masyarakat dengan tema pengolahan data berbantu software SPSS bagi perangkat desa di kecamatan Buntu Pane kabupaten Asahan :

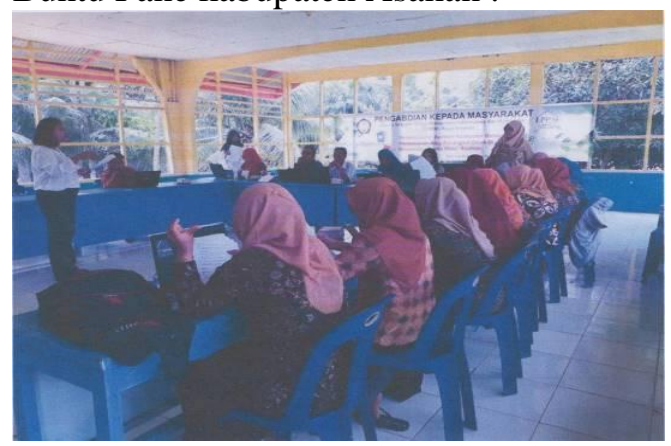

Gambar 4. Penyampaian materi oleh narasumber

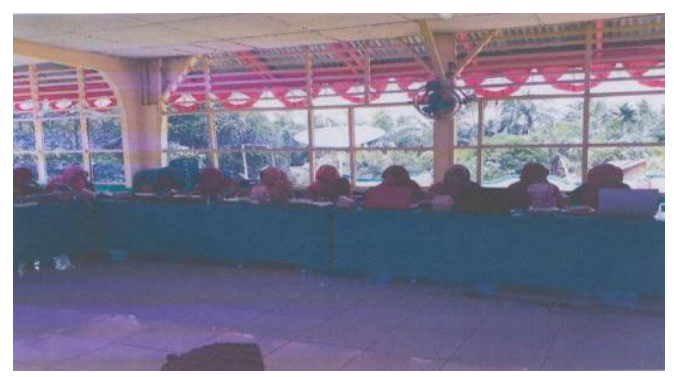

Gambar 5. Kegiatan pengolahan data

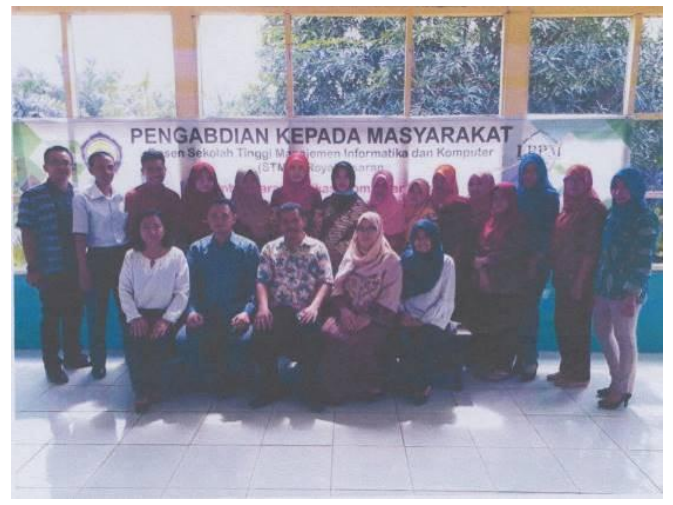

Gambar 6. Foto bersama peserta kegiatan PKM

\section{SIMPULAN}

Kegiatan pengabdian kepada masyarakat yang dilakukan di Kecamatan Buntu Pane kabupaten Asahan sukses dilakukan sebagaimana yang diharapkan. Para perangkat desa sebagai peserta yang mengikuti kegiatan pelatihan pengolahan data mampu menguasai materi dan mengimplementasikan menggunakan Software SPSS. Penguasaan materi secara menyeluruh mulai dari perkenalan software dan cara menjalankkannya, menginputkan data dan mengolah data tersebut merupakan modal dasar bagi para perangkat desa Buntu Pane dalam mengambil keputusan dimasa yang akan datang. Pengembangan selanjutnya para peserta bisa melanjutkan pelatihan tentang pengolahan data dengan kasus-kasus yang lebih kompleks

\section{UCAPAN TERIMA KASIH}

Kegiatan ini merupakan hasil dari kerjasama antara sivitas akademika STMIK Royal dengan perangkat desa Kecamatan Buntu Pane Kabupaten Asahan serta bantuan materi, tenaga, dan fikiran dari berbagai pihak. Untuk itu, Tim pengabdian kepada masyarakat 
Vol. 1, No. 2, Jul 2018, hlm. 41 - 44

ISSN 2614-7912 (cetak)

Available online at http://jurnal.stmikroyal.ac.id/index.php/jurdimas

STMIK Royal Kisaran mengucapan terima kasih yang sebesarbesarnya kepada:

1. Bapak Anda Putra Lubis, SE., MMA, Ketua Yayasan Royal Teladan Asahan, sebagai penyandang dana,

2. Bapak Ruslan, SH, camat Buntu Pane Kab. Asahan, sebagai mitra kegiatan pengabdian kepada masyarakat,

3. Tim pengabdian kepada masyarakat yang telah bekerjasama dengan baik, sehingga kegiatan dapat berjalan lancar dan sukses.

\section{DAFTAR PUSTAKA}

Besral. (2010). Pengolahan dan Analisa Data menggunakan SPSS. Jakarta
: Departemen Biostatistika-

Fakultas kesehatan masyarakat UI.

LPPM. (2017). Format Penulisan Jurdimas. Kisaran : STMIK Royal.

Kurniawan, Bobi. (2017). Program IPTEK bagi Inovasi dan reativitas Kampus IT Training and Service Centre (ITSC) UNIKOM (JPKM, Vol. 3 No. 1.Hal 18-25).

Tim Pusar data dan Statistik Pendidikan. (2014). Modul Pembelajaran SPSS. Jakarta : Pusat data dan Statistik Pendidikan Kemendikbud RI. 